\title{
A adivinhação e as origens do pensamento científico na China
}

\author{
RICARDO MÁRIO GONÇALVES \\ Departamento de História \\ Faculdade de Filosofia, Letras e Ciências Humanas \\ Universidade de São Paulo
}

\begin{abstract}
RESUMO: Este artigo apresenta um quadro geral da antiga civilização chinesa, inserindo no mesmo a problemática das práticas divinatórias e suas relações com o pensamento cientifico, cujas origens remontam à época da Dinastia Chang ou Yin (1708-1059 a.C.), focalizada mais detalhadamente neste trabalho. Datam dessa época os mais antigos textos da civilizaçăo chinesa - textos divinatórios que nos informam sobre a vida politica, as crenças religiosas, a estrutura social e também sobre os primeiros ensaios do pensamento científico no Extremo Oriente como, por exemplo, a elaboração dos primeiros calendários. Ao término do artigo, apresentase o l-Ching (Livro das Mutações) e sua utilização nas artes divinatórias chinesas.

PALAVRAS-CHAVE: China antiga, adivinhação, pensamento científico, Dinastia Chang, I-Ching (Livro das Mutações).
\end{abstract}

\section{Introdução}

Quando fomos convidados a apresentar um trabalho sobre a adivinhação e o pensamento científico na China arcaica, duas possibilidades se colocavam. Poderíamos apresentar um texto puramente técnico, recheado de ideogramas chineses arcaicos e modernos e, nesse caso, dificilmente se encontraria no Brasil editora com recursos gráficos para imprimi-lo e leitores aptos a compreendê-lo. A outra alternativa, pela qual optamos, consiste em apresentar um quadro geral da antiga civilização chinesa, tão pouco conhecida e estudada entre nós, inserindo no mesmo a problemática das práticas divinatórias e suas relações com o pensamento científico. Encerraremos este trabalho com uma apresentação do I-Ching (Livro das Mutações) e sua utilização nas artes divinatórias chinesas.

A civilização tradicional chinesa desenvolveu uma rica tradição científica que hoje está sendo estudada por uma série de historiadores da ciência de renome internacional como Joseph Needham (1984-85), na Inglaterra, e Kiyoshi Yabuuchi (1982), no Japão. Os diferentes ramos do saber científico (Matemática, Astronomia, Medicina etc.) constituíram-se 
durante a Dinastia Han (202 a.C. - 280 d.C.), época em que foram redigidos os mais antigos tratados científicos sistemáticos. Entretanto, as origens da tradição científica chinesa remontam a uma época bem mais antiga, a da Dinastia Chang ou Ying (1700 1059 a.C.), época que focalizaremos detalhadamente no decorrer deste trabalho. Datam dessa época os mais antigos textos da civilização chinesa - textos divinatórios que nos informam sobre a vida política, as crenças religiosas, a estrutura social e também sobre os primeiros ensaios do pensamento científico no Extremo Oriente como, por exemplo, a elaboração dos primeiros calendários.

\section{A civilização chinesa da Idade do Bronze: a Dinastia Chang e suas artes divinatórias ${ }^{1}$}

Depois de longos séculos de culturas neolíticas (tradições de Yang-Shao e LongChan) que se iniciam por volta de 5000 a.C., a China entra na história com a metalurgia do bronze por volta de 1700 a.C., sob a égide de uma linhagem real cujos soberanos se designavam por Chang mas que receberam o nome de Yin quando da queda de sua dinastia.

O poder dos reis Chang remonta a mais ou menos 1700 a.C.. Na época de seu maior poder, sua capital era a cidade de An-Yang, cujas escavações arqueológicas foram iniciadas em 1928. Era uma cidade monumental, impressionante por suas dimensões e edificações, e situava-se na bacia inferior do Rio Amarelo, numa região em que desde o Neolítico produziam-se belas cerâmicas brilhantes que exigiam um cozimento em altas temperaturas, o que atesta o grande avanço técnico das artes do fogo. Conhecemos essa sociedade graças ao material arqueológico encontrado nas grandes tumbas reais escavadas desde 1934 .

As pesquisas realizadas até o presente momento nos permitem supor que se tratava de uma sociedade inteiramente submetida ao poder temporal e espiritual de um poderoso chefe que, no seu palácio, durante a vida, e no seu túmulo, depois da morte, reunia as mais importantes riquezas - homens e objetos - das regiões que controlava. Mostrava-se atento à vontade do Céu, da natureza em geral e dos ancestrais e nada decidia - nem mesmo as grandes caçadas a que se mostrava particularmente aficionado - sem consultar os oráculos. As práticas divinatórias utilizadas pelos Chang remontavam à época neolítica e compreendiam basicamente a escapulimancia e a quelonimancia, que consistem em expor à ação do fogo, respectivamente, omoplatas de cervos e carapaças de tartarugas para ler as respostas das questões propostas nas rachaduras provocadas pelo calor das chamas. Tais práticas foram utilizadas também em regiões da periferia do mundo chinês como Manchúria, Coréia, Tibete e Japão. Neste último país, a prática da escapulimancia, denominada Futomani, subsiste até hoje em alguns santuários xintoístas. Foi dessas práticas divinatórias, da necessidade de comunicar e conservar fórmulas mágicas que nasceu a escrita na China. Derivados simplificados de representações mais ou menos realistas, os primitivos pictogramas rapidamente tende- 
ram, principalmente quando se tratava de exprimir conceitos abstratos, a tomar as formas convencionais de uma espécie de estenografia. Os adivinhos chineses costumavam escrever nos ossos e nas carapaças de tartaruga as perguntas e as respostas, bem como as datas em que as consultas eram feitas.

A utilização de carapaças de tartaruga na arte divinatória está ligada à importância simbólica desse animal na cultura chinesa. A tartaruga é considerada na China uma espécie de miniatura do Cosmos, já que sua carapaça inferior, de forma quadrangular, lembra a Terra (simbolizada pelo quadrado) e a superior, de forma arrendondada, lembra o Céu (simbolizado pelo círculo). Os chineses da época Chang usavam para suas práticas carapaças de uma tartaruga gigante, hoje em dia só encontrada na Malásia A arte divinatória da época parece estar, de alguma forma, vinculada aos ritos agrários, já que as tartarugas utilizadas na mesma eram caçadas durante o outono, época do amadurecimento dos vegetais e dos trabalhos da colheita.

A descoberta das inscrições divinatórias data de 1899 e desde os primeiros anos de nosso século têm sido elas minuciosamente estudadas por investigadores. Os caracteres em que foram escritas são ancestrais dos ideogramas da escrita chinesa atual e qualquer pessoa familiarizada com estes últimos, com um pouco de treino, pode lê-las sem grandes dificuldades.

Os ossos eram geralmente divididos em quadrantes por traços em $\mathrm{T}$, traçados de um lado e de outro da linha mediana e numerados de 1 a 5 ou mais. $O$ verso apresentava alvéolos num dos quais se aplicava um tição ardente para provocar uma rachadura. Esta era marcada então por um termo técnico como "pequeno augúrio", "grande augúrio" ou "augúrio superior" (chang-hi). O texto é sempre dividido em duas partes: na parte direita, em colunas que se lêem da esquerda para a direita, colocava-se a pergunta: na parte esquerda, em colunas lidas da direita para esquerda, a resposta. Apresentamos, à guisa de exemplo, a tradução de um inscrição divinatória:

Adivinhação do dia $\sin -y u$ [ $58^{\circ}$ de um ciclo de 60 dias]. [O adivinho] Pin interroga: Tche [?] e Hua, do país de Shu [?] [podem] suscitar prejuizos para Kio?

Resposta:

Tche [?] e Hua, do país de Shu [?], não devem suscitar prejuízos para Kio.

$\mathrm{O}$ adivinho Pin, um dos mais citados nos textos oraculares durante um período de três séculos, parece ter vivido sob o reinado de Wu-Ting (1339-1281 a.C.). Os países de Shu e Kio são citados em outras inscrições, sempre a propósito de disputas, agressões e expedições punitivas. Tche e Hua são provavelmente nomes de pessoas que aparecem também em outras inscrições, separadamente ou juntos. O trabalho de deciframento permite discernir o sentido dos caracteres arcaicos mas nem sempre é possivel associálos a caracteres mais recentes cuja pronúncia seja conhecida. Daí os pontos de interrogação que nos lembram que a proposta de pronúncia de um determinado nome é problemática. 
O que conhecemos hoje sobre a civilização Chang se deve não só ao estudo das inscrições divinatórias mas também às numerosas campanhas arqueológicas realizadas após o advento da China Popular em 1949. Sabemos hoje que a China descobriu o metal - o cobre - no início do segundo milênio antes de nossa era. As crônicas e anais dos historiógrafos mencionam, antes do advento dos Chang, a existência de uma primeira dinastia denominada Hsia que, antes das campanhas arqueológicas empreendidas pelo governo da China Popular, era considerada uma tradição mítica. Hoje em dia, baseados na análise do material encontrado nos sítios arqueológicos de Eul-li-tou e Eul-li-gang, onde se descobriu uma cultura de transição do Neolítico para a Idade dos Metais, alguns especialistas estão inclinados a aceitar a Dinastia Hsia como uma realidade histórica, embora até o presente momento ainda seja impossível discernir seus limites precisos.

Ossos de mamíferos contendo ou não inscrições divinatórias descobertos por acaso já eram, há muitos séculos, tradicionalmente incorporados à farmacopéia chinesa com o nome de "ossos de dragão". Reduzidos a pó, eram considerados eficazes na cura da malária e outras moléstias graves. No fim do século XIX, depois de cheias particularmente violentas, as terras de aluvião da bacia do Rio Amarelo se abriram, revelando a existência de numerosos objetos de bronze e de ossos com inscrições. O erudito Wang Yi-Jong (1848-1900) adquiriu grande quantidade desses ossos, que a partir de 1899 atraíram a atenção do mundo letrado. Filólogos chineses como Lo Tchen-Yu, Wang Kuo-Wei e Tong Tso-Pin e historiadores japoneses como Torajiro (Konan) Naito começaram um longo e paciente trabalho de deciframento e análise das inscrições.

Os objetos de arte da época - vasos de bronze e insígnias de jade - nos fazem imaginar uma sociedade solene e estática, mas as inscrições divinatórias nos fazem entrever, pelo contrário, movimentos violentos de oposição, centralizados em questões oraculares, entre um partido conservador e uma facção progressista, ligados a questões inerentes à administração de um grande reino.

Segundo o sistema divinatório mais antigo, tal como era praticado sob o $22^{\circ}$ soberano da dinastia, Wu-Ting (1339-1281 a.C.), a data dos sacrificios era fixada com nove dias de antecedência. Se, no último momento, se manifestasse um sinal de mau agouro, tal como a chuva, por exemplo, a cerimônia era adiada; era preciso escolher um novo dia, sempre com nove dias de antecedência. Os sacrificios eram muito numerosos e as consultas oraculares abrangiam todos os detalhes da administração e da vida cotidiana, de uma maneira geral. Respostas desagradáveis provocavam contrariedades na vida administrativa e provocavam tensões entre o rei e os adivinhos; todas as ações de importância viam-se consideravelmente retardadas. Por isso o $24^{\circ}$ soberano Tsu-Kia (12731245 a.C.) realizou uma reforma, estabelecendo para cada sacrificio um dia determinado dentro de periodos de dez dias, levando em conta correspondências numéricas atribuídas aos ancestrais das grandes famílias.

O rei foi paulatinamente simplificando e reagrupando os sacrificios e fixou um calendário, o que representou uma grande revolução religiosa e um fator de grande importância para a coordenação das tarefas do agricultor. Antes de analisar o calendário 
Chang, cumpre lembrar, de passagem, que existem três tipos possiveis de calendários: 0 lunar (por exemplo, o calendário islâmico), o solar (por exemplo, o calendário gregoriano que usamos atualmente) e o misto ou luni-solar, cujos exemplos mais significativos são os calendários babilônico e chinês. A semelhança existente entre os calendários da China e da Babilônia tem sido inclusive apontada como um argumento a favor da tese da origem médio-oriental da cultura chinesa, defendida por alguns arqueólogos e historiadores. Outro argumento seria a semelhança entre a cerâmica do Neolítico chinês com a de alguns sitios arqueológicos da URSS como os de Anau e Tripolié, já notada por J. G. Anderson, o descobridor das culturas neolíticas chinesas, no período entre as duas guerras mundiais.

Além de sistematizar os sacrificios e de impor um calendário, o rei fez-se pontífice, encarregando-se pessoalmente de expor ao fogo os ossos e carapaças de tartaruga, o que além de colocá-lo em contato direto com o mundo do sagrado, apresentava a grande vantagem prática e política de evitar as longas esperas administrativas e de enfraquecer o poder de sacerdotes e adivinhos.

O calendário Chang, ancestral dos calendários mais perfeitos das eras posteriores, compreendia 12 meses numerados de 1 a 12 , e às vezes um mês suplementar, a princípio colocado no fim do ano, mas depois deixado móvel pelos reformadores, o que permitia fixar com melhor precisão as datas dos trabalhos agrícolas. Os meses dividiam-se em grandes, de 30 dias, e em pequenos, de 29 dias. Além dos meses, os Chang tinham semanas de 10 dias (décadas) e ciclos de 60 dias, sendo cada dia designado por um duplo signo astrológico resultante da combinação de uma série de 10 com outra de 6 símbolos. A utilização desse sistema de numeração sexagesimal é mais um traço que aproxima a China da Mesopotâmia. Era costume consultar os oráculos no início de cada década, a respeito do caráter auspicioso ou nefasto da mesma. Em algumas inscrições oraculares encontramos informações sobre eclipses, o que mostra que os Chang já estavam ensaiando os primeiros passos rumo à constituição de um saber astronômico. Encontramos também anotações referentes aos equinócios e à passagem das estações. $\mathrm{O}$ início do ano coincidia com o advento da primavera. Entretanto, o calendário ainda era bastante imperfeito e as discrepâncias entre o ano oficial e o ciclo anual das atividades agrícolas só eram eliminadas parcialmente com a instituição dos meses suplementares. No período Chang o mês suplementar era estabelecido de forma bastante irregular. Só muito depois, a partir do século IV. a.C., os chineses elaboraram a regra segundo a qual sete meses suplementares deveriam figurar em cada ciclo de 19 anos.

As carapaças de tartarugas divinatórias e o bestiário dos vasos de bronze, comportando tigres, rinocerontes e elefantes, nos ensinam que no período Chang a bacia inferior do Rio Amarelo, que hoje apresenta um clima continental, gozava de um clima quente e úmido, favorável à vida e ao desenvolvimento de uma grande civilização. Representações antropomórficas em alguns jarrões de bronze nos permitem concluir que as tribos Chang eram morfologicamente próximas dos habitantes atuais da China Meridional. Nas duas margens do rio os monarcas estabeleceram suas capitais. Conhe- 
cemos hoje de cinco a sete capitais sucessivas, sendo que de duas delas subsistem importantes vestígios.

Uma das mais antigas é Tcheng-chou, descoberta em 1950 na província de Honan, ao sul do Rio Amarelo; parece tratar-se da "cidade de Ao", capital do $10^{\circ}$ rei da dinastia, no século XV a.C. Parece ter sido construída à semelhança das grandes aldeias do Neolítico final. Era protegida por muros de terra batida e seu plano era em tabuleiro de xadrez, como a maior parte das cidades chinesas até nossos dias. Junto do recinto murado, que formava um quadrilátero de $2 \mathrm{~km}$ de lado, foram encontrados esqueletos de 150 cães sacrificados por ocasião dos ritos de fundação. A cidade parece ter abrigado grande número de artesãos: metalúrgicos especializados no trabalho com o bronze, talhadores de ossos e de jade e ceramistas.

Um século mais tarde o $19^{\circ}$ soberano, P'an-Keng, transferiu a capital para AnYang, a primeira cidade dos Chang a ser escavada a partir de 1928. A cidade abrangia uma grande superficie e seus muros ainda não foram descobertos. Comportava grande número de vastos palácios, em torno dos quais agrupavam-se moradias semi-subterrâneas, de forma oval. No subsolo dos templos dedicados aos ancestrais das grandes familias e no dos palácios reais encontram-se numerosas ossadas de vítimas sacrificadas nos ritos de fundação: cães, gado e seres humanos, dentre os quais numerosas crianças pequenas. Tais vítimas eram sacrificadas para que seu sopro vital animasse as novas edificações, das quais se tornariam os espiritos tutelares. Tais práticas atestam o desenvolvimento, desde essa época, de uma noção posteriormente depurada e aperfeiçoada nas diferentes escolas de filosofia chinesa: a do valor universal, cósmico, do sopro vital animador de toda a matéria.

$\mathrm{O}$ além, concebido como uma réplica da existência terrestre, revestia-se para os Chang de particular importância, a julgar pela grandiosidade e riqueza dos túmulos reais encontrados na região. Os mais espetaculares são os doze túmulos reais encontrados em An-Yang. Alguns mediam $10 \mathrm{~m}$ de largura e mais de $40 \mathrm{~m}$ de comprimento. No seu interior encontraram-se folhas de ouro, baixelas e armas de bronze, esculturas de jade e de outras pedras, cerâmica etc. Os reis faziam-se acompanhar, em sua viagem para o além, por numerosos guardas armados e servidores, cujos corpos decapitados foram encontrados em fossos dispostos em volta do sarcófago real. As cabeças das vítimas eram enterradas à parte.

Esses numerosos sacrificios humanos e as inscrições divinatórias atestam existência da escravidão, não de uma escravidão semelhante à do mundo clássico, capaz de suportar a hipótese de um modo de produção escravista proposto pelo historiador marxista Kuo Mo-Jo, mas uma forma de escravidão doméstica pouco relevante para a vida econômica. Os textos divinatórios designam os escravos por expressões geográficas como Kiang, Yang, Si etc. Elas indicam que os habitantes dessas regiões eram aprisionados e depois escolhidos como vítimas expiatórias para os diferentes sacrificios. Os prisioneiros de guerra eram portanto designados pelos nomes de suas tribos de origem e constituíam uma mão de obra doméstica que representava também uma reserva de vítimas a serem sacrificadas para acompanharem ao além-túmulo seus amos falecidos. 
Os textos divinatórios, com exceção daqueles que tratam de expedições guerreiras ou venatórias promovidas pelos reis, não mencionam os escravos. Também não mencionam trabalhos forçados agrícolas ou artesanais a que fossem submetidas as populações vencidas. Também não se mencionam indivíduos passíveis de serem comprados e vendidos. As tribos vencidas e seus territórios caiam sob a autoridade do rei, representante da divindade clânica.

Parece que a organização do trabalho e das relações humanas sob os Chang repousava sobre a repartição das tarefas entre vários clãs principais grupados em pirâmide. No topo da mesma encontramos o rei, que encarnava o Homem por excelência, mediador entre o Céu e a Terra. De sua conduta e de seu escrúpulo em realizar ritualmente, em primeiro lugar, os atos fundamentais da vida como as tarefas agrárias do plantio e da colheita, dependia a manutenção da boa ordem no mundo e a marcha regular das estações.

Em tomo do rei ordenava-se sua numerosa família, composta por esposas, muitos filhos e irmãos. Estes últimos podiam ser chamados a sucedê-lo. Governadores de territórios (pan-po), preceptores (tchejang), adivinhos (pu) escribas (che), feiticeiros ( $w u$ ), sacerdotes $(t c h u)$ e altos funcionários pertenciam também ao clã real. Os mais importantes nessa hierarquia eram os adivinhos, escribas e sacerdotes, responsáveis por todos os negócios do Estado e mediadores entre a divindade suprema e seus assessores.

O clã real era o "Grande Clã" (Ta Tsong) que encontrava apoio e obediência em outros agrupamentos menos poderosos, os "Pequenos Clãs" (Siao Tsong). Todos juntos formavam uma comunidade sedentária, agrária e civilizada que se opunha a uma plêiade de tribos bárbaras (Yi). Estes constituiam um perigo constante e crescente: as inscrições divinatórias nos dão conta de um incessante fenômeno de pressão exercida sobre a China sedentária pelas tribos nômades, que notamos em todas as épocas da história do pais.

Remontam ao período Chang os primeiros ensaios na constituição de um saber filosófico e mesmo científico, a partir de conceitos religiosos. A análise filológica dos textos divinatórios nos permite detectar a forma mais arcaica de certas noções que vieram a se constituir em fundamentos da tradição chinesa.

Originalmente parece ter existido um culto primitivo de natureza totêmica, apelando às forças misteriosas do Universo para vencer a adversidade. Pouco a pouco o conhecimento de certos fenômenos naturais foi mostrando ao homem que o saber poderia resolver uma série de problemas da vida prática. $O$ recurso à experiência dos mais velhos suscitou o respeito aos anciãos, prelúdio do culto dos ancestrais que se somou ao das demais forças da natureza divinizadas.

A divindade suprema era o "Grande Ancestral" ou "Soberano do Alto" (ChangTi), ao qual correspondia o "Soberano de Baixo" (Hia-Ti). Entre o Céu (Tien) e a Terra (Ti) estabeleceu-se um parentesco que fez do soberano o "Filho do Céu" (Tien-tze), sobre o qual convergiam as virtudes das divindades e os poderes dos ancestrais. $O$ respeito a estes últimos foi paulatinamente esboçando um sentimento 
que permaneceu profundamente enraizado na alma chinesa de todas as épocas: a piedade filial (hiao).

O ideograma hiao, que exprime o conceito de piedade filial desde a época das inscrições divinatórias é homógrafo de kao (antigo) e de lao (velho). Entra ainda na composição do ideograma kiao (doutrina ou ensinar). Essa associação de ideogramas mostra muito bem a devoção dos Chang aos anciãos sob a forma de respeito aos ensinamentos deles recebidos. $\mathrm{O}$ culto dos ancestrais, celebrado por ocasião dos aniversários, reforçava os laços de consangüinidade no interior do clã e criava para as outras comunidades menos desenvolvidas obrigações de obediência e deferência.

A partir dessa idéia de obediência formou-se o conceito de $t e h$ (virtude), que teve um papel muito importante ao longo do desenvolvimento do pensamento chinês. Nos ossos divinatórios o conceito de teh é muitas vezes expresso pelo ideograma siun (seguir, obedecer) que muitas vezes é confundido com tche (retidão, justiça). Teh compreende portanto os sentidos de "aquilo que convém", "aquilo que é justo". No período Chang teh exprimia a qualidade fundamental segundo a qual se regulavam as relações entre os homens, a essência do que existe no humano. Daí deriva outra noção fundamental do pensamento chinês, a de $l i$ (rito, norma de etiqueta ou de cortesia).

As inscrições divinatórias representam o conceito de li por um pictograma representando pedras de jade dentro de um vaso: trata-se de instrumento de oferenda, do ritual, da norma de conduta, dos bons costumes. Muitas vezes era lembrado que a oferenda não precisava ser rica e séculos depois o historiógrafo Ssu-ma T'sien (c. 145-90 a.C.) lembrou isso, dizendo que a maneira de dar vale mais do que aquilo que é dado.

Em função de teh e de $l i$, os soberanos Chang, desejosos de descobrir uma legitimação superior para seu poder, fundaram seu governo sobre duas idéias essenciais: a essência do humano justifica as regras de conduta (teh-tche); as regras de conduta permitem realizar a essência do humano (li-tche). Não aceitavam nenhum julgamento e nenhum limite a sua soberania, exceto a do "Soberano do Alto" (Chang-Ti), deus, senhor do Universo e divindade ancestral do clã.

Cumpre lembrar que a partir desses dados não surgiu nenhuma grande religião nacional. $O$ culto dos ancestrais continuou sendo o núcleo da atividade religiosa chinesa até o século XX. A filosofia política e moral e os estudos literários passaram a ser o principal interesse das elites dominantes, ao passo que entre o povo continuaram a imperar as velhas crenças xamânicas e mágicas.

Por volta do ano 1100 a.C., os Chang foram suplantados por um jovem e aguerrido clã originário do Oeste, das terras do alto Rio Amarelo: os Tchou. Principiava a época que iria assistir a uma importante revolução cultural da qual nasceria a tradição chinesa tal como a conhecemos hoje em dia, centralizada em torno de Confúcio. 


\section{O l-Ching e sua utilização na arte divinatória ${ }^{2}$}

Foge aos objetivos de nosso trabalho estendermo-nos longamente sobre a história da China a partir dos Tchou, quando as práticas e inscrições divinatórias desaparecem da cena. Entretanto, seria incompleto o estudo sobre a adivinhação chinesa na antiguidade que não dedicasse algumas páginas ao célebre I-Ching (Livro das Mutações), amplamente difundido no Ocidente a partir dos estudos que a ele dedicou Carl Gustav Jung, o pai da Psicologia Analítica, em parceria com o sinólogo Richard Wilhem.

Confúcio (Kung Fu-tze, 551-479 a.C.), o pai da filosofia moral e política chinesa, deu também especial atenção ao desenvolvimento dos estudos literários e históricos. Seu interesse pela história antiga da China vinha do fato de ela apresentar uma série de exemplos de boa conduta a serem imitados pela posteridade. A tradição fez dele o compilador e o editor de cinco importantes clássicos, a saber: o Livro dos Documentos, o Livro das Odes, o Livro dos Ritos, os Anais das Primaveras e Outonos (crônica do principado de Lu, terra natal do filósofo) e, finalmente, o I-Ching ou Livro das Mutações.

O I-Ching se apresenta como um conjunto de 64 símbolos (hexagramas), sobre os quais discorreremos mais adiante, acompanhados de comentários e glosas. A invenção dos hexagramas é atribuída ao sábio $\mathrm{Fo}-\mathrm{Hi}$, um dos legendários fundadores da civilização chinesa. Os comentários mais antigos seriam de autoria do rei Wen, o primeiro soberano Tchou, e de seu filho, o Duque de Tchou, venerado por Confúcio como um dos grandes sábios da antiguidade. As glosas mais recentes seriam de autoria do próprio Confúcio.

$\mathrm{Na}$ realidade, o I-Ching é uma sintese de velhas idéias cosmológicas que remontam ao período Chang, sistematizadas posteriormente numa escola de cosmologia e adivinhação, a Escola do Yin-Yang, que só seria completamente organizada sob a Dinastia Han.

Os letrados confucianos sempre utilizaram o I-Ching como um texto para reflexões filosóficas e morais, desaconselhando seu uso nas artes divinatórias. Entretanto, este último foi sempre extremamente difundido entre as classes populares, não só na própria China como também nos países vizinhos como a Coréia e o Japão. Recentemente, as teorias de C. G. Jung contribuíram para popularizar sua utilização também no Ocidente. As traduções do mesmo mais lidas no mundo ocidental são a de James Legge (1962) para o inglês e a de Richard Wilhelm (1973) para o alemão, esta última (celebrizada pelos comentários psicológicos de C. G. Jung) traduz o I-Ching num jargão psicanalítico e foi vertida para muitos idiomas, inclusive para o nosso (Correia Pinto, s.d.). Existe ainda uma tradução portuguesa de autoria de Pe. J. A. Guerra S.J. (1984), de Macau, bastante fiel ao texto original.

A escola cosmológica do Yin-Yang originou-se nos círculos ocultistas que desde a Dinastia Tchou, e talvez até antes, se ocupavam de magia, adivinhação, astrologia e numerologia. Tais disciplinas ocultas têm em comum com a ciência o fato de terem 
sido talvez a origem de um certo desejo de interpretar a natureza e torná-la útil para o homem. A princípio de forma muito rudimentar, mas depois com progressiva sofisticação, procuraram analisar a origem e a estrutura do Universo culminando numa explicação dos fenômenos em torno de forças naturais. Posicionaram-se então muito próximas da ciência, que constitui uma tentativa de compreensão racional do desconhecido. Os ocultistas chineses desenvolveram uma teoria bastante dinâmica segundo a qual o homem poderia impôr-se à natureza através de uma investigação das leis cósmicas, não para conformar-se a elas, mas sim para dominá-las.

Uma das linhas de pensamento desenvolvidas pelos ocultistas chineses procura explicar a origem do Universo. A partir do Tao (caminho, curso), ou "Não-Ser" Primordial, surge o "Ser" primeiro, simbolizado pela Unidade. Esta bifurca-se e dá origem aos dois princípios fundamentais da criação diversificada, o Yin (feminino) e o Yang (masculino). Os conceitos de Yin e Yang parecem ter se originado da experiência cotidiana dos agricultores chineses da época arcaica. Yang teria sido originalmente uma face de uma montanha voltada para o sol, quente e iluminada, e Yin a face oposta, sombria, fria e úmida. Para representar-se o Yang utilizou-se uma linha horizontal contínua, pois os números Yang são ímpares, e para o Yin uma linha quebrada em duas, pois os números Yin são pares:

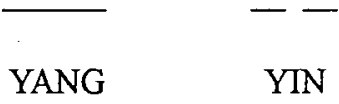

Alguns sinólogos do século passado propuseram uma origem babilônica para essas notações, através da escrita cuneiforme, mas hoje essa hipótese deve ser descartada. A origem de tais representações estaria simplesmente nas fissuras provocadas pelo fogo nas carapaças de tartaruga e ossos divinatórios do Periodo Chang. As rachaduras únicas indicariam respostas positivas e as duplas, respostas negativas.

Os ocultistas chineses classificaram todas as realidades do universo da natureza e da cultura em termos de Yin e Yang. Vejamos os exemplos mais significativos:

\begin{tabular}{lll}
\hline & & - \\
YANG & & YIN \\
Céu & & Terra \\
Sol & & Lua \\
Luz & & Trevas \\
Primavera & Outono \\
Verão & & nverno \\
Dia & & Noite \\
Adiante & & Atrás \\
Superior & & Inferior \\
Alto & & Baixo
\end{tabular}




$\begin{array}{ll}\text { Dinâmico } & \text { Estático } \\ \text { Nobre } & \text { Vil } \\ \text { Felicidade } & \text { Infortúnio } \\ \text { Homem } & \text { Mulher } \\ \text { Esposo } & \text { Esposa } \\ \text { Pais } & \text { Filhos } \\ \text { Soberano } & \text { Súdito } \\ \text { Forte } & \text { Fraco } \\ \text { Interior } & \text { Exterior }\end{array}$

Essas classificações não são fixas e estáveis, mas sim cambiantes, mutáveis, dando idéia de um universo em perpétua transformação. Assim, uma mãe é Yin em relação a seu marido mas é Yang em relação a seu filho. $O$ homem é bem-sucedido em seus assuntos terrenos, ou seja, torna-se Yang em relação à Terra quando se mostra Yin em relação ao Céu. Fracassa, porém, ou torna-se Yin em relação à Terra quando se mostra Yang em relação ao Céu.

Os ocultistas chineses, combinando traços Yang e Yin em grupos de três, obtiveram oito combinações ou trigramas, que receberam denominações de fenômenos da natureza:

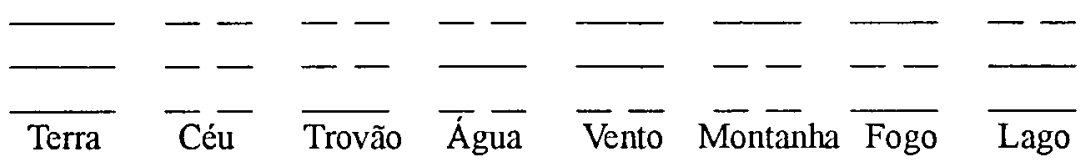

Juntando os trigramas em grupos de dois obtemos 64 combinações de seis linhas ou hexagramas. São os símbolos que compoem o I-Ching. Trigramas e hexagramas mostram a passagem dos eventos de um estado para o outro: são eventos que se transformam sem cessar. Acredita-se que através dos hexagramas seja possivel conhecer as tendências do movimento natural das coisas. Cada situação na existência demanda um comportamento adequado e os hexagramas, transposições sintéticas das realidades da vida, permitem, segundo os adivinhos, conhecer a conduta a seguir em casos concretos. Trata-se, pois, de um sistema divinatório muito mais complexo que a escapulimancia e a quelonimancia, que só fornecem respostas afirmativas ou negativas.

Já mencionamos os comentários e glosas que acompanham os hexagramas no I-Ching. Compreendem textos breves denominados tuan que dão uma explicação geral de cada hexagrama e comentários referentes a cada linha dos mesmos, denominados yao, termo que significa "mudar", "entrecruzar".

O conjunto formado pelos hexagramas, os tuan e os yao constitui, segundo a tradição chinesa, uma fonte de conselhos para a conduta correta do homem. Acredita-se que pelo I-Ching o homem conhece o germe dos fatos enquanto estes permanecem em estado latente, numa fase em que ainda é possivel dominá-los antes que se tornem realidades demasiadamente poderosas. A idéia fundamental sugerida pelo I-Ching é a 
de um Universo em constantes mutações que se refletem no homem. Conhecendo os símbolos do $I$-Ching o sábio chinês pode mergulhar nos segredos da vida e da morte e atingir uma serenidade que o distingue das pessoas vulgares, sempre inquietas e atormentadas pela incerteza.

Lembremos ainda que dos 64 hexagramas do I-Ching apenas o primeiro, denominado "Criador", formado de seis traços Yang, e o segundo, chamado "Receptivo", contruído por seis linhas Yin, são absolutamente homogêneos, isto é, o primeiro totalmente Yang e o segundo completamente Yin. Todos os demais combinam traços Yin e Yang, o que mostra que para os antigos chineses todos os fatos da vida eram relativos: para eles nada era inteiramente positivo ou negativo, existindo luz em potencialidade no meio das trevas e vice-versa. Essas idéias do I-Ching foram retomadas e desenvolvidas na Idade Média pelos grandes mestres do Budismo C'han (Zen).

O I-Ching primitivo não mencionava as designações Yin-Yang, usando em seu lugar as denominações "flexível" e "rigido", respectivamente. Yin e Yang foram designações que surgiram posteriormente ao texto do I-Ching e pertencem ao sistema divinatório em sua fase mais tardia, despido de todo o fundo religioso e interpretado dos pontos de vista metafísico, cosmológico e ético pelos letrados confucianos. O confucionismo é uma filosofia que não rejeita o sobrenatural mas coloca-o à distância e encoraja uma atitude racionalista perante a vida, encarando com desprezo as superstições irracionais. Essa releitura racionalista do I-Ching tem seus princípios expostos nos apêndices confucianos ao livro, em que o Yin e o Yang são definidos como aspectos do mundo visível e invisivel cujas alternâncias constituem o Tao ou Princípio Cósmico Primordial. Em suas manifestações concretas, consistem eles no Céu (Yang) e na Terra (Yin). Além disso, a releitura confunciana do $I$-Ching via na obediência aos comportamentos prescritos pelo texto uma questão de conduta dentro da sociedade e não um problema de conseguir a felicidade e afastar o infortúnio. Dai a desconfiança dos letrados em relação ao uso divinatório do $I$-Ching. O que importava aos intelectuais confucianos era o cumprimento do dever social e não a felicidade ou a desgraça pessoal. Existe, assim, uma grande diferença entre o I-Ching original, religioso e individualista, e a releitura confuciana, racionalista e humanista por natureza.

Para terminar, basta expor, rapidamente, algo a respeito dos métodos de trabalho dos adivinhos chineses com o I-Ching. No método mais tradicional, usam-se cinquenta galhos da planta do milefólio (achillea ptarmica). Na falta dessa planta muito rara mesmo na própria China, usam-se simplesmente varetas de bambu. Depois de purificar-se com abluções, queimar incenso e proferir uma breve fórmula de saudação ao Duque de Tchou e a Confúcio, o adivinho separa o feixe de ramos em dois grupos. Retira então um galho de um dos grupos, segurando-o entre o quarto e quinto dedo da mão esquerda. É o símbolo da Unidade Primordial. Abandonando um dos grupos, vai retirando do outro feixes de quatro grupos. $O$ número de galhos restantes no fim da operação indica uma linha Yin, se for par, uma Yang, se for impar. Obtém-se assim a primeira linha do hexagrama, que é sempre construido de baixo para cima, da linha 
inferior para a superior. Costuma-se repetir a operação três vezes para cada linha, a título de confirmação. São necessárias pois dezoito manipulações para se obter um hexagrama.

Sendo esse método extremamente complicado, criou-se outro, mais simples, em que se jogam moedas de cobre, inscritas de um lado e lisas do outro. O lado inscrito é considerado Yin e o oposto, Yang.

Esperamos ter conseguido fornecer ao leitor uma noção geral das artes divinatórias da China antiga e das relações das mesmas com os primeiros ensaios de pensamento científico levados a cabo naquele país. Em suma, vimos como as práticas divinatórias do período Chang estão ligadas à origem da escrita, a rudimentos de um saber astronômico e à elaboração dos primeiros calendários. Vimos também como a releitura confuciana do I-Ching representa um passo no sentido de uma compreensão racional da natureza e de seus processos.

\section{Notas}

1-Esta exposição é uma condensação de: Elisseeff, 1987, p. 38-93; Kaisuka, 1972; e Yabuuchi, 1982.

2- Esta exposição é uma condensção de: Joppert, 1978, p. 123-33; Hattori, 1972 e 1975.

\section{Referências Bibliográficas}

ELISSEEFF, Vadime, e Danielle. La Civilisation de la Chine Classique. Paris: Arthaud, 1987. GUERRA, Joaquim A. de Jesus. O livro das mutações. Macau: Jesuitas Portugueses, 1984. HATTORI, Ryutaro. Eki to Jujutsu [O I-Ching e a magia]. Tóquio: Shinjimbutsu Jurai-sha, 1972. HATTORI, Ryutaro. Eki to Nihonjin [O I-Ching e os japoneses]. Tóquio: Yuzankaku, 1975. JOPPERT, Ricardo. O alicerce cultural da China. Rio de Janeiro: Avenir, 1978.

KAIZUKA, Shigeki. Kodai Yin Teikoku [O antigo Império Yin]. Tóquio: Mimizu Shobô, 1972. LEGGE, James. The I-Ching. New York: Dover Publications, 1962.

NEEDHAM, Joseph. Science and Civilization in China. Cambridge, Mass.: Cambridge University Press, 7 v., 1984-1985.

WLHELM, Richard. I-Ging. Regensburg: Eugen Diederichs Verlag, 1973.

WILHELM, Richard. I-Ching, o livro das mutações. Trad. de Gustavo A. Correia Pinto. São Paulo: O Pensamento, s.d.

YABUUCHI, Kiyoshi. Kagaku-shi kara mita Chûgoku bunmei [A civilização chinesa vista pela História da Ciência]. Tóquio: NHK, 1982. 
GONÇALVES, R. M. La divination et les origines de la pensée scientifique en Chine. Clássica, São Paulo, 4: 67-80, 1991.

RÉSUMÉ: Cet article présente un cadre général de la civilisation chinoise ancienne, en y soulignant le problème des pratiques divinatoires et leur rapport avec la pensée scientifique, dont les origines remontent à l'époque de la Dinastie Chang ou Yin (1700-1059 a.C.), étudiée plus en détail dans ce travail. De cette époque datent les plus anciens textes de la civilisation chinoise - textes divinatoires qui nous renseignent au sujet de la vie politique, des croyances religieuses, de la structure sociale et aussi sur les premiers essais de la pensée scientifique en Extrême Orient comme, par exemple, l'élaboration des premiers calendriers. Au terme de cet article, on présente le 1-Ching (le Livre des Mutations) et son utilization dans les arts divinatoires chinoises.

MOTS CLÉS: Chine ancienne, divination, pensée scientifique, Dinastic Chang, /Ching (Livre des Mutations). 